\title{
Surgical treatment of congenital blepharoptosis
}

\author{
Tratamento cirúrgico da blefaroptose congênita
}

\author{
Suzana Matayoshi', Ivana Cardoso Pereira², Luiz Angelo Rossato ${ }^{2}$
}

\begin{abstract}
The blepharoptosis is the improper positioning of the upper eyelid, being below its normal position in primary gaze, which is $0.5-2 \mathrm{~mm}$ below the superior corneal limbus. It may block partially or completely the upper visual field, and lead to aesthetic commitment. The causes are categorized as congenital or acquired. It is considered congenital if present at birth or diagnosed during the first year of life. The main techniques used for the treatment of congenital ptosis are the resection of the levator muscle aponeurosis and the frontalis suspension. The function of the levator muscle is the most important parameter to define the surgical technique. When the function is weak, the frontalis suspension is more appropriate; the supra-maximal resection of the levator muscle may also be employed. With function above 4 or $5 \mathrm{~mm}$, the resection of the aponeurosis is preferred. For the frontalis suspension surgery, various materials can be used, so we present a comparison of the most relevant studies. We also discuss some characteristics in more complicated cases, such as the Blepharophimosis syndrome and the Marcus-Gunn syndrome, and surgical techniques less performed and complications reported.

Keywords: Blepharoptosis/congenital; Blepharoptosis/surgery; Blepharoptosis/ complications; Eyelid/pathology
\end{abstract}

\section{ReSUMO}

A blefaroptose é o posicionamento inadequado da pálpebra superior, estando abaixo de sua posição normal na posição primária do olhar, a qual seria $0,5-2 \mathrm{~mm}$ abaixo do limbo superior. Pode causar bloqueio parcial ou completo do campo visual superior, além do comprometimento estético. As causas são categorizadas em congênitas ou adquiridas. É considerada congênita se presente ao nascimento ou diagnosticada no primeiro ano de vida. As principais técnicas utilizadas para o tratamento da ptose congênita são a ressecção da aponeurose do músculo levantador da pálpebra superior (MLPS) e a suspensão frontal. A medida da função do MLPS é o parâmetro mais importante na escolha da técnica cirúrgica. Quando a função é fraca, a suspensão frontal é mais indicada; a ressecção supramáxima do MLPS também pode ser empregada. Acima de 4 ou $5 \mathrm{~mm}$ de função do MLPS, prefere-se a ressecção da aponeurose. Para a cirurgia de suspensão frontal, vários são os materiais utilizados, portanto apresentamos uma comparação entre os estudos mais relevantes. Discutiremos também particularidades em casos mais complicados, como as Síndromes da Blefarofimose e de Marcus-Gunn, além de técnicas cirúrgicas menos utilizadas e as complicações relatadas.

Descritores: Blefaroptose/congênito; Blefaroptose/cirurgia; Blefaroptose/complicações; Pálpebra/patologia

\footnotetext{
1 Oculoplastic Surgery Unit, Medical School, São Paulo University, São Paulo/SP, Brazil.

${ }^{2}$ Postgraduate Programme, Department of Ophthalmology, Medical School, São Paulo University, São Paulo/SP, Brazil.
}

Work conducted at the University Hospital of the São Paulo University, São Paulo/SP, Brazil.

The authors declare no conflict of interest. 


\section{INTRODUCTION}

B lepharoptosis is characterised by improper positioning of the upper eyelid below its normal position, $0.5-2 \mathrm{~mm}$ below the superior limbus in the primary position of gaze (PPG).(1) The lowered eyelid margin can partially or completely block the upper visual field in the PPG and in downgaze, and it can also cause cosmetic problems.

The difference between the position of the upper eyelid margin with ptosis and the position of a normal eyelid (covering the corneal limbus by $2 \mathrm{~mm}$ at the 12 o'clock position) was one of the first parameters taken into consideration in the semiology of ptosis by Beard ${ }^{(2)}$, who classified the condition into mild (1.5$2 \mathrm{~mm}$ ), moderate $(3 \mathrm{~mm})$, and severe (ee4 $\mathrm{mm})$.

Because this measurement can be inaccurate as the examiner needs to manually lift the eyelid, Sarver and Putterman $^{(3)}$ suggested using the marginal reflex distance (MRD-1), which is the distance between the upper eyelid margin and the centre of the pupil. A normal MRD-1 is between 2.6$4.4 \mathrm{~mm}$, with lower values characterising ptosis. ${ }^{(4)}$ Nonetheless, other factors should also be taken into account, such as presence of facial and/or eyelid asymmetry, the patient's facial proportions, and ethnicity.

The patient unconsciously tries to compensate for the ptosis by contracting the frontalis and corrugator muscles, changing head position by raising the chin, or even lifting the eyelids and/ or eyebrows with his/her fingers. Constant stimulation of facial muscles can cause tension.

The prevalence of ptosis is similar for both genders and across different races. The risk factors for the condition are: age, diabetes, myasthenia gravis, and brain tumour, all of which can affect neural or muscle responses. ${ }^{(5)}$

Ptosis can be classified as congenital or acquired. It is considered to be congenital when present at birth or when diagnosed within the first year of life. Acquired ptosis is further divided into anatomical, neurogenic, mechanical, traumatic, and myogenic. ${ }^{(6,7)}$

The anatomical structures involved in upper eyelid elevation include three muscles: the levator palpebrae superioris (LPS) (the main muscle, innervated by the oculomotor nerve), Müller's smooth muscle (sympathetic innervation, responsible for up to $2 \mathrm{~mm}$ of elevation), and the frontalis muscle (which is innervated by the facial nerve and has a secondary function in eyelid elevation).

Eyelid ptosis is treated surgically, and the procedure is based on the three above-mentioned muscles. Surgery can be indicated for functional or cosmetic reasons. It is an elective procedure that needs to be planned taking into account its risks and benefits.

The preferred technique and its outcomes depend on the type of ptosis, LPS function, age, laterality, the presence of additional ophthalmic or neurological abnormalities, and the surgeon's preference. The three most common procedures are: levator aponeurosis resection-reinsertion; Müller's muscle resection (conjunctival mullerectomy or tarsal-conjunctival mullerectomy); and frontalis suspension. ${ }^{(5,6)}$ These techniques will be presented and discussed throughout this paper.

\section{Clinical features of congenital ptosis}

Congenital ptosis often results from a failure in the embryonic development of the LPS muscle. This muscle is initially formed from the superior rectus muscle during embryogenesis and reaches its normal position around the fourth month of pregnancy. The first abnormalities appear during this period. Müller's muscle is also formed at this stage. In congenital myogenic ptosis LPS fibres are dystrophic and replaced by fibrous tissue. ${ }^{(8)}$

Unlike acquired ptosis, congenital ptosis has different characteristics depending on the position of gaze: it is accentuated in upgaze, while in downgaze it shows lid lag (the muscle does not relax normally), and the eyelid crease is absent in most cases. ${ }^{(9)}$

The initial evaluation of children with congenital ptosis includes an assessment of marginal reflex distance (MRD-1), LPS excursion, height of the upper eyelid crease, Bell's phenomenon, and the presence of conditions such as Marcus Gunn syndrome and associated vertical strabismus. ${ }^{(1)} \mathrm{A}$ significant decrease in LPS function (4 $\mathrm{mm}$ or less) is usually observed. Although ptosis is not considered a progressive condition, children with ptosis have a higher incidence of amblyopia (14-23\%) and other developmental visual disorders such as myopia, astigmatism, anisometropia, torticollis, and strabismus. $^{(10)}$

Ptosis is unilateral in $70 \%$ of cases and can be associated with changes in one or more extraocular muscles and/or systemic diseases. More severe cases involve hypoplasia of the LPS or its aponeurosis, with an absent or attenuated eyelid crease. ${ }^{(6)}$

Measurement of LPS function, i.e. eyelid excursion, is the most important parameter when choosing the surgical technique. Child cooperation is required for an accurate measurement.

\section{Surgical treatment of congenital ptosis}

Reports from the $19^{\text {th }}$ century already described the surgical treatment of congenital ptosis. Bowman first reported on LPS resection in 1857, and Dransart described the first frontalis suspension in 1880. In 1909, Payr introduced the use of autologous fascia lata, which was later reintroduced by Wright in 1922. In 1966, Tillet and Tillet first described the use of silicone in frontalis suspension to correct ptosis. In the mid- $20^{\text {th }}$ century, authors such as Berk, Jones and Beard systematised surgical techniques and concepts. ${ }^{(11)}$

\section{Currently, the most common techniques are LPS resection and frontalis suspension.}

When there is no risk or sign of amblyopia, surgical correction can be performed at the age of 3-5 years, when eyelid structures are well developed and the fascia lata can be removed. If amblyopia is present, however, ptosis correction should be performed at an early age, and an alloplastic material can be used as a temporary sling until the patient is old enough for autologous fascia lata grafting.

\section{Resection of LPS aponeurosis}

In the traditional approach to aponeurosis resection, a horizontal incision measuring approximately $20-22 \mathrm{~mm}$ is made on the skin, the orbicularis muscle is dissected, the septum is opened, and the aponeurosis is identified as the pink-white structure underneath the eyelid fat. It is then resected at the intended height and subsequently advanced up to the middle third of the tarsal plate with three U-shaped sutures positioned in the central, medial and lateral regions. ${ }^{(1)}$

In order to better identify and individualise the aponeurosis, $2 \%$ lidocaine with a vasoconstrictor (1:200000 adrenaline) can 
be injected in the subconjunctival space, allowing the surgeon to easily separate the LPS aponeurosis from the conjunctiva-Müller's muscle complex. A small horizontal incision of the aponeurosis in the upper third of the tarsus followed by medial and lateral extension helps disconnect the aponeurosis from the tarsus. Oblique cuts made vertically along the medial and lateral horns of the aponeurosis help move it anteriorly. A Berke forceps can be used to manipulate the aponeurosis (Figure 1).

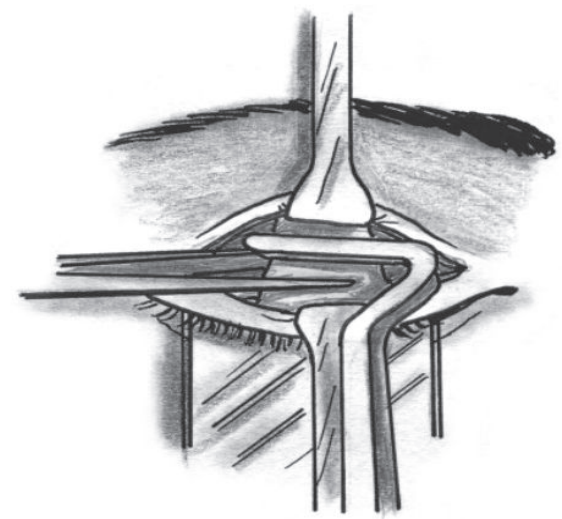

Figure 1. LPS aponeurosis resection using a Berke forceps.

Non-absorbable sutures should be used, as absorbable sutures can lead to late surgical failure. ${ }^{(12)}$

An eyelid crease or fold can be created by suturing the upper margin of the skin, the aponeurosis and the skin in the lower incision margin. Three to four sutures are usually applied.

The major question in this kind of procedure is the amount of aponeurosis to be resected, which is highly dependent on surgeon's experience. The resection can be small (10-13 mm), medium (14-20 mm), or large (e"21 mm); LPS function and the degree of ptosis should be used as parameters. The resection table proposed by Beard ${ }^{(1)}$ can be used to determine resection size (Table 1).

\section{Table 1}

Degree of ptosis and amount of LPS aponeurosis resection

\begin{tabular}{lcc}
\hline $\begin{array}{l}\text { Degree of } \\
\text { ptose }(\mathbf{m m})\end{array}$ & LPS & Procedure \\
\hline
\end{tabular}

$\begin{array}{lcc}\text { Mild (1,5-2,0) } & \text { Good }(\geq 8) & \text { Ressecção } 10-13 \mathrm{~mm} \\ & \geq 8 & \text { Ressecção } 14-17 \mathrm{~mm} \\ \text { Moderate (3,0) } & 5-7 & \text { Ressecção } 18-22 \mathrm{~mm} \\ & \leq 4 & \text { Ressecção } \geq 23 \mathrm{~mm} \\ \text { Severe }(\geq 4) & & \\ & & \text { Ressecção } \geq 23 \mathrm{~mm} \\ & 5-7 & \text { Ressecção } \geq 23 \mathrm{~mm}\end{array}$

\section{This technique has two variants:}

1) Whitnall's ligament suspension: the aponeurosis is resected up to Whitnall's ligament and the tarsus is sutured directly to the ligament. This procedure is indicated when LPS function is between $4-5 \mathrm{~mm}$. Its drawback is that Whitnall's ligament works as a mobile "sleeve" for the LPS muscle, turning its horizontal force into a vertical force for the upper eyelid. Dissecting the medial and lateral pillars of the ligament can compromise its supporting role. ${ }^{(13)}$ The eyelid can evert if the suture is placed too close to the lower border of the tarsus.

2) Supramaximal resection of the aponeurosis: more than $30 \mathrm{~mm}$ of tissue are resected, including the aponeurosis and the LPS muscle. In order to release the posterior part of the ligament, its adhesion is resected medially and laterally. The dissection should not damage the superior rectus muscle. ${ }^{(14)}$ This is an alternative to frontalis suspension that avoids the risk of infection and extrusion and does not require removal of the fascia lata, thus avoiding an additional scar and reducing the duration of surgery.

\section{Frontalis suspension}

Frontalis suspension is widely used to repair ptosis with poor LPS function and good frontalis muscle function. It is used primarily for congenital ptosis, but also for blepharophimosis syndrome and neurogenic ptosis (third cranial nerve palsy and Marcus Gunn syndrome). ${ }^{(10,15)}$ The procedure connects the motor unit (frontalis muscle) to the upper eyelid (Figure 2).

Most techniques use skin incisions at the tarsus and eyebrow levels to insert the sling material in the suborbicularis

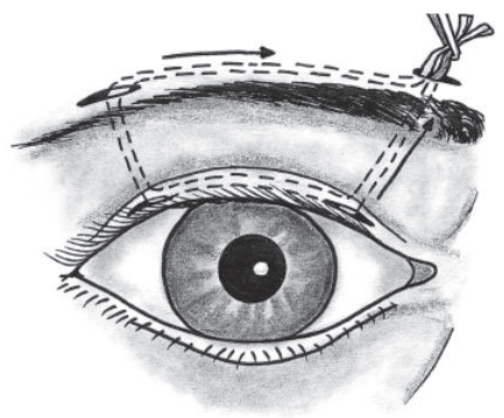

Figure 2. Frontalis suspension. The arrow indicates the point where the sling material ends are joined together at the head of the eyebrow.

plane. ${ }^{(10)}$ The material is placed anteriorly to the orbital septum plane, so that the eyelid is raised towards the eyebrow instead of along the eye surface, decreasing the interaction between the eyelid and the cornea. A "hood" can also be formed under the pre-tarsal and pre-septal skin, delaying eyelid lowering in downgaze. ${ }^{(6)}$

The sling material may become loose, which reduces its function and effectiveness. Asian patients are more prone to eyelid inversion following frontalis suspension surgery. ${ }^{(16)}$

\section{Endogenous versus exogenous materials}

The most commonly used materials are preserved or nonpreserved fascia lata or temporal fascia, the palmaris longus tendon, and the umbilical vein. Different exogenous materials have been used for suspension, such as silicone, nylon, collagen, silk, and stainless steel sutures and Mersilene (Ethicon, Blue Ash, $\mathrm{OH}, \mathrm{EUA}$.), Supramid (nylon polyfilament, S. Jackson, Alexandria, VA, EUA) and Gore-Tex (polytetrafluorethylene W.L. Gore and Associates, Newark, DE, EUA) mesh. ${ }^{(17)}$

Autologous fascia lata has a minimal risk of infection, extrusion or rupture, and also a greater viability time and compatibility, although it requires a second surgical incision. ${ }^{(16)}$ The patient should be at least 3 years old, so that their leg size is 
sufficient for removing an appropriate fascia. ${ }^{(16,18)}$ A fascia lata allograft is another option, but it shows higher (8-63.2\%) rates of recurrence compared to autologous fascia lata $(0.8-5 \%)$, especially in the long term. ${ }^{(10,13,19)}$ Preserved fascia lata can be replaced by a fibrous tissue, producing a permanent effect, but it can also be absorbed prematurely, and it involves the risk of transmitting infectious diseases. While several authors consider the fascia lata to be the best material for frontalis suspension ${ }^{(10)}$, others prefer silicone. ${ }^{(20)}$

Silicone is a readily accessible, adjustable and elastic material, which makes it convenient for frontalis suspension in conditions coursing with mild Bell's phenomenon such as chronic progressive external ophthalmoplegia, myasthenia gravis, and third cranial nerve palsy. ${ }^{(20)}$ A silicone suture on the tarsus has the benefits of lower migration and thus lower recurrence rates, and is also important for creating an eyelid crease. ${ }^{(21)}$

Table 2 shows a summary of studies comparing the different materials used in frontalis suspension. Note that the results are highly variable for the rates of recurrence and complications. Until 2005, the fascia lata was almost unanimously considered the best material, but more recent studies tend to prefer silicone due to its superior cosmetic outcomes and lower recurrence rates. $^{(21)}$ Still, prospective randomised trials are required to confirm the superiority of silicone over the fascia lata ${ }^{(21)}$ and to compare silicone with other materials.

Studies have shown that nylon, Mersilene and polytetrafluorethylene (PTFE or "Gore-tex") also have good acceptance, but show varying rates of extrusion, infection, and granuloma formation. ${ }^{17,19,22)}$

Autologous fascia lata remains the preferred material for most surgeons and is considered the gold-standard procedure. ${ }^{(7,10,16,18,23)}$ Preserved fascia lata is the second-best option. ${ }^{(23)}$ Even though eyelid height, contour, and creasing seem to be satisfactory in the early postoperative period, the cosmetic outcome can change over time, mainly as regards the symmetry of eyelid height in unilateral cases and eyelid creasing in unilateral and bilateral cases, even when the functional outcome remains good. Other authors, however, report good long-term functional outcomes, with preserved eyelid height and creasing. ${ }^{(16)}$

\section{Sling Design}

Various suture designs can be used, including: single triangle, double triangle, single rhomboid (Friedenwald-Guyton procedure), double rhomboid (Iliff procedure), double

Table 2

Comparison of different materials used for frontalis suspension

\begin{tabular}{|c|c|c|c|c|}
\hline & $\mathbf{N}$ & 'Follow-up' (months) & Recorrence rate (\%) & Complications (\%) \\
\hline Wasserman (2001) ${ }^{(17)}$ & 34 & & & \\
\hline Autologous fascia & & 30 & 4,2 & 8,3 \\
\hline Preserved fascia & 18 & 51.4 & 5,7 & \\
\hline Polypropylene & & 24 & 12,5 & 0 \\
\hline Nylon & & 24 & 69.2 & 7,7 \\
\hline Mersilene & & 8 & 27.3 & 9,1 \\
\hline Polytetrafluorethylene & & 6 & 0 & 45.5 \\
\hline \multicolumn{5}{|l|}{ Lee (2009) } \\
\hline Preserved fascia & 63 & 36 & $41.4-63.2$ & \\
\hline Silicone & 60 & 36 & 29.2 & \\
\hline Ben Simon (2005) ${ }^{(22)}$ & 27 & & & \\
\hline Autologous fascia & & $>20$ & 22 & 0 \\
\hline Nylon & & 20 & 25 & 5 \\
\hline Silicone & & $>20$ & 44 & 42.9 \\
\hline Polytetrafluorethylene & & 20 & 15 & 11.1 \\
\hline Wagner (1984) ${ }^{(24)}$ & 42 & & & \\
\hline Preserved fascia lata & & 20,8 & 8,3 & 0 \\
\hline Nylon & & 31.5 & 28.1 & 12.4 \\
\hline \multicolumn{5}{|l|}{ Berry-Brincat (2009) ${ }^{(25)}$} \\
\hline Mersilene & 28 & 30 & 17.02 & 0 \\
\hline \multicolumn{5}{|l|}{ Mehta (2004) (26) } \\
\hline Mersilene & 12 & 32 & 27 & 20 \\
\hline Juncedo-Moreno (2005) ${ }^{(27)}$ & 12 & & & \\
\hline Autologous fascia & 18 & & & 5 \\
\hline Preserved fascia & 23 & & & \\
\hline Silicone & 15 & & & \\
\hline Polytetrafluorethylene & 20 & & & 40 \\
\hline
\end{tabular}


trapezoid (Wright procedure), single pentagon (Fox procedure), and double pentagon (Crawford procedure). ${ }^{(16,23)}$ Some authors believe the single triangle procedure is preferred for pointed eyebrows and the pentagonal or rhomboid procedures are preferred for diffusely elevated eyebrows. Other, however, recommend the single triangle procedure (modified Fox procedure) for children and the double triangle (modified Crawford procedure) for adults. ${ }^{(23)}$ There are also authors who recommend the single rhomboid procedure for small children, as it prevents postoperative eyelid folds. ${ }^{(10)}$ Ben Simon et al. found no differences in terms of recurrence rates, function, or cosmetics between the single rhomboid loop and the double pentagon. ${ }^{(22)}$ The Crawford procedure is recommended for fascia lata grafting, and the Fox procedure is recommended for alloplastic material. Crease incisions showed better outcomes regarding eyelid contour and crease symmetry than supraciliary incisions. ${ }^{(22)}$

\section{Bilateral versus unilateral surgery in severe unilateral ptosis}

Some authors recommend bilateral frontalis suspension for the treatment of unilateral congenital ptosis, claiming that it results in improved symmetry when closing the eyes, blinking, and gazing downward. ${ }^{(16,18)}$ However, bilateral surgery puts both eyes at risk of postoperative complications such as lagophthalmos, exposure keratitis, upper eyelid entropion, eyelash ptosis, absent eyelid crease, excess skin, and superior oblique muscle palsy. Other authors suggest that unilateral surgery preserving the healthy side is more likely to be accepted by parents, as well as being a shorter procedure with lower risks. The presence of spontaneous eyebrow elevation on the affected side preoperatively can be predictive of successful unilateral frontalis suspension. Unilateral surgery is recommended for unilateral congenital ptosis with poor LPS function and without amblyopia. ${ }^{(28)}$ Patients with amblyopia are at risk of under-correction when subjected to unilateral surgery, therefore bilateral frontalis suspension is the procedure of choice in these cases. ${ }^{(16)}$

\section{Other less commonly used techniques}

\section{Tarsectomy}

According to Reifler ${ }^{(29)}$, tarsectomy was first described by Gillet de Grandmont in 1891. It has become popular over the past twenty years because it can be flexibly combined with either posterior resection of LPS aponeurosis ${ }^{(30,31)}$ or posterior Müller's muscle resection (Fasanella-Servat, 1961). ${ }^{(32)}$ It has also been described as a technique for correcting recurrent ptosis and ptosis unresponsive to other usual techniques. ${ }^{(31)}$ Tarsectomy involves vertical eyelid shortening, which elevates the eyelid margin. Tarsal resection should preserve at least $3 \mathrm{~mm}$ from the eyelid margin in order to maintain eyelid stability. ${ }^{(32)}$

\section{Frontalis transfer}

This technique involves a dynamic flap of the frontalis muscle tunneled to the upper eyelid and sutured to the tarsal plate; it is used in cases of congenital and/or acquired ptosis which recurs after correction using other procedures and whose LPS function is under $4 \mathrm{~mm} .^{(6,7,19)}$ The frontalis muscle is dissected from the periosteum and from the orbicularis muscle, the orbital septum is separated from the orbital margin, and a semielastic pulley is created to accommodate the flap. ${ }^{(19)}$ The LPS muscle is advanced and folded over the aponeurosis for a distance of 12-
$16 \mathrm{~mm}$. The flap is sutured to the tarsal plate using non-absorbable 6-0 or 7-0 sutures (three stitches: centre of pupil, lateral limbus and medial limbus). The eyelid margin is adjusted so it remains at the level of the upper limbus, and patients need to learn how to position their eyelid in a functional and cosmetic fashion. Reported complications include reduced eyelid excursion on extreme upgaze and downgaze (primarily in the immediate postoperative period), bleeding due to frontalis muscle dissection, denervation, donor site deformities with eyebrow asymmetry, supraciliary scar, and lagophthalmos. There are no reports of corneal exposure. Eyelid symmetry is more frequently achieved in bilateral procedures. ${ }^{(7,19)}$ This procedure can be performed in younger children, as the frontalis muscle is adequately developed by the age of two. ${ }^{(6)}$

\section{Indications for surgical techniques}

Current recommendations for congenital ptosis correction vary, but frontalis suspension is recommended for children younger than 3-4 years of age with poor LPS function. The options for children with LPS function under $3 \mathrm{~mm}$ include frontalis suspension, frontalis muscle flap, and Whitnall's ligament suspension. The LPS muscle can be resected or advanced in patients whose LPS function is over $5 \mathrm{~mm}$. Whitnall's ligament suspension (with or without tarsectomy) can be performed in cases of relapse after frontalis suspension, and vice versa.

The greatest difficulties occur when indicating surgery for cases with LPS function between 5 and $7 \mathrm{~mm}$, since resection of the LPS aponeurosis may not be sufficient. Alternatives include frontalis suspension, maximal LPS resection, and Whitnall's ligament suspension alone or combined with superior tarsectomy. ${ }^{(20,30)}$

\section{Surgery for blepharophimosis syndrome}

Patients with blepharophimosis syndrome usually present with epicanthus inversus, horizontal and vertical narrowing of the palpebral fissures, telecanthus, and severe ptosis (LPS hypoplasia). Other associated changes include strabismus, amblyopia, high-arched eyebrows, ear deformities, hypogonadism, and infertility. ${ }^{(33)}$

Where possible, correction of telecanthus and epicanthus should precede ptosis correction because the palpebral fissure height can decrease with surgical manipulation ${ }^{(34)}$ (Figure 3).

Frontalis suspension with fascia lata grafting is the most indicated procedure. ${ }^{(33)}$ Some authors report good experiences with supramaximal LPS resection. ${ }^{(14)}$

Even in successful cases, blepharophimosis patients retain a typical facies with narrower palpebral fissures.



Figure 3. Blepharophimosis. Note the marks of epicanthus inversus correction. Severe ptosis with arched eyebrows, reduced horizontal fissure, and euryblepharon. 


\section{Marcus Gunn syndrome}

Marcus Gunn syndrome is a trigeminal-oculomotor synkinesis consisting of unilateral congenital ptosis in which the eyelid retracts when the ipsilateral pterygoid muscle is stimulated. This stimulation can occur when the patient opens his/her mouth, chews, sucks, smiles, moves the jaw laterally to the affected and/or unaffected site, protrudes the tongue or jaw, and contracts the sternocleidomastoid muscle. ${ }^{(35)}$ Although bilateral cases exist, they are rare. The condition's prevalence is similar for both genders and sides of the face, being observed in $2-13 \%$ of patients with congenital ptosis. It is believed to be caused by a deviation of one branch of the fifth cranial nerve to the third cranial nerve, but other cranial nerves can also be involved. Some patients learn how to control the position and excursion of the affected eyelid. ${ }^{(15)}$

It is classified according to upper eyelid excursion during mouth stimulation, measured in millimetres: mild $(<2 \mathrm{~mm})$, moderate $(2-5 \mathrm{~mm})$, and severe $(>5 \mathrm{~mm})$. When the syndrome results in functional or cosmetic impairment, surgical treatment should be considered, such as LPS excision (aponeurosis and terminal muscle) in the affected site and weakening or excision of the contralateral LPS, followed by bilateral frontalis suspension. ${ }^{(15,36)}$ For patients who do not want to undergo bilateral surgery or non-amblyogenic patients, the procedure can be performed only in the affected side, although it can result in eyelid asymmetry in downgaze. Patients submitted to bilateral surgery show better upper eyelid symmetry in the primary position of gaze. ${ }^{(36)}$

Associated changes such as treatable amblyopia (23-59\% of patients), vertical strabismus (23-48\%) and horizontal strabismus (34\%) should be resolved beforehand. ${ }^{(36)}$ If the jawwinking synkinesis causes only minor cosmetic problems it can be ignored, and ptosis treatment should be done by simply using the appropriate techniques for each degree of LPS function. If the synkinesis is moderate to severe and causes problems to the patient, it should be taken into account in the choice of surgical treatment. For mild synkinesis, treatment includes observation, LPS resection, or the Fasanella-Servat procedure. ${ }^{(15)}$

The LPS aponeurosis has a number of connections underneath Whitnall's ligament and divides the lacrimal gland into its orbital and palpebral sections. Therefore, LPS excision is not always complete, and the connections between the LPS and the eyelid can be restored. This is why some authors recommend excising the aponeurosis and the terminal LPS associated with bilateral frontalis suspension. This would lead to a better outcome due to the symmetrical weakness of upper eyelids, symmetrical frontalis suspension, and the use of the frontalis muscle to elevate both upper eyelids. ${ }^{(36)}$

\section{Complications of ptosis surgery}

The most common complication is under-correction (10$15 \%$ of cases), which can result from improper resection, incorrect identification of structures, excessive scarring, or improper suturing $^{(6,7)}$ (Figure 4). Over-correction results in incomplete eyelid occlusion and is a rare complication of congenital ptosis correction, but it can occur when the eyelid is sutured to Whitnall's ligament or when the orbital septum is excessively shortened.(7) Although it is desirable postoperatively, symmetrical eyelid height can expose the cornea, therefore it is recommended that a Frost



Figure 4. Under-correction of left ptosis 15 days after resection of the LPS aponeurosis.

suture is made at the end of surgery and removed after 48 hours.

Other complications include transient or permanent diplopia in cases of residual third cranial nerve palsy, adverse reaction to anaesthetics, intra- or postoperative bleeding, infectious processes, mild keratitis and corneal abrasion secondary to improper suturing, reactions to alloplastic materials (Figure 5), or suture abscess. Absent or low eyelid creasing can be secondary to an improper incision or a failure in crease formation, and eyelid margin distortions can be secondary to asymmetric aponeurosis advancement. ${ }^{(6)}$ Late complications include eyelid asymmetry and foreign-body sensation.

Eyelash ptosis, entropion and excessive skin folding can also occur. Fixation of the fascia to the lower tarsus creates an anterior torque on the eyelid margin and reduces the risk of entropion, but it can lead to a euryblepharon-like opening of the margin. Creating an eyelid crease is also important. In order to prevent skin folding, excessive skin should be removed as appropriate. ${ }^{(16)}$

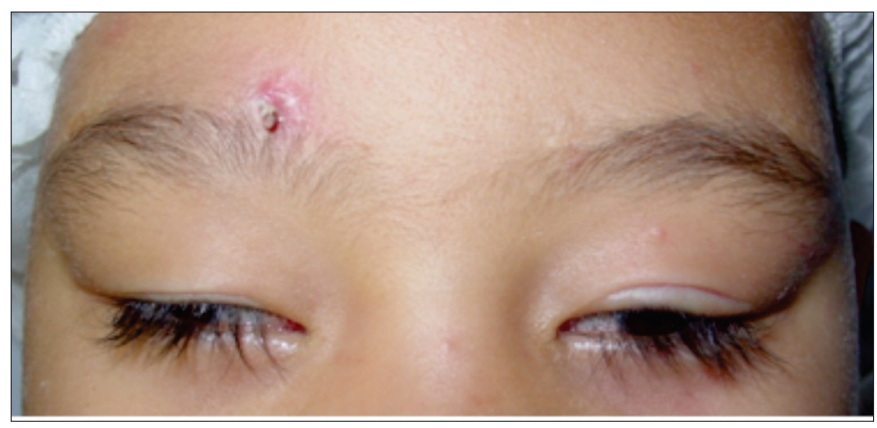

Figure 5. Reaction to silicone with a local inflammatory process and partial exposure of the material.

\section{Conclusion}

The major techniques used in the treatment of congenital ptosis are resection of the LPS aponeurosis and frontalis suspension. When amblyopia is present the ptosis needs to be corrected early; otherwise, it can be corrected after three years of age.

Measurement of LPS function, i.e. eyelid excursion, is the most important parameter when choosing the surgical technique. Frontalis suspension is indicated when LPS function is poor; alternatively, supramaximal resection of the LPS muscle can also be employed. Aponeurosis resection is the preferred technique in patients whose LPS function is around $4-5 \mathrm{~mm}$.

Outcomes are less effective in patients with 
blepharophimosis syndrome than in simple congenital ptosis. Bilateral frontalis suspension is still the most used technique, although supramaximal resection of the LPS can also be considered for such cases. For Marcus Gunn syndrome, maximal resection of the LPS in combination with frontalis suspension produces the best results.

Under-correction is the most frequent complication, followed by crease deformities, lagophthalmos, keratopathy, implant extrusion, and granuloma formation (associated with alloplastic materials in frontalis suspension).

Even though the literature on the subject is vast, the lack of controlled randomised studies on the different surgical techniques and alloplastic or homologous materials hinder a more objective analysis and the selection of the best approach in the treatment of congenital ptosis.

\section{RefERENCES}

1. Callahan MA, Beard C. Beard's ptosis. 4a ed. Birmingham: Aesculapius; 1990.

2. Beard C, Sullivan JH. Ptosis—current concepts. Int Ophthalmol Clin. 1978;18(3):53-73. Review.

3. Sarver BL, Putterman AM. Margin limbal distance to determine amount of levator resection. Arch Ophthalmol. 1985;103(3):354-6.

4. Frueh BR. Graves' eye disease: orbital compliance and other physical measurements. Trans Am Ophthalmol Soc. 1984;82:492598. Review.

5. Finsterer J. Ptosis: causes, presentation, and management. Aesthetic Plast Surg. 2003;27(3):193-204. Review.

6. Allard FD, Durairaj VD. Current techniques in surgical correction of congenital ptosis. Middle East Afr J Ophthalmol. 2010;17(2):129-33.

7. Baroody M, Holds JB, Vick VL. Advances in the diagnosis and treatment of ptosis. Curr Opin Ophthalmol. 2005;16(6):351-5. Review.

8. Baldwin HC, Manners RM. Congenital blepharoptosis: a literature review of the histology of levator palpebrae superioris muscle. Ophthal Plast Reconstr Surg. 2002;18(4):301-7. Review.

9. Meyer DR, Rheeman CH. Downgaze eyelid position in patients with blepharoptosis. Ophthalmology. 1995;102(10):1517-23.

10. Takahashi Y, Leibovitch I, Kakizaki H. Frontalis suspension surgery in upper eyelid blepharoptosis. Open Ophthalmol J. 2010;4:91-7.

11. Gonzalez MO, Durairaj VD. The history of ptosis surgery. In: Cohen AJ, Weinberg DA. Evaluation and management of blepharoptosis. New York: Springer; 2011.

12. Frueh BR, Musch DC, McDonald HM. Efficacy and efficiency of a small-incision, minimal dissection procedure versus a traditional approach for correcting aponeurotic ptosis. Ophthalmology. 2004;111(12):2158-63. Review.

13. Holmström H, Bernström-Lundberg C, Oldfors A. Anatomical study of the structures at the roof of the orbit with special reference to the check ligament of the superior fornix. Scand J Plast Reconstr Surg Hand Surg. 2002;36(3):157-9.

14. Epstein GA, Putterman AM. Super-maximum levator resection for severe unilateral congenital blepharoptosis. Ophthalmic Surg. 1984;15(12):971-9.
15. Demirci H, Frueh BR, Nelson CC. Marcus Gunn jaw-winking synkinesis: clinical features and management. Ophthalmology. 2010;117(7):1447-52.

16. Yoon JS, Lee SY. Long-term functional and cosmetic outcomes after frontalis suspension using autogenous fascia lata for pediatric congenital ptosis. Ophthalmology. 2009;116(7):1405-14.

17. Wasserman BN, Sprunger DT, Helveston EM. Comparison of materials used in frontalis suspension. Arch Ophthalmol. 2001;119(5):687-91.

18. Bernardini FP, Devoto MH, Priolo E. Treatment of unilateral congenital ptosis. Ophthalmology. 2007;114(3):622-3.

19. Ramirez OM,Peña G. Frontalis muscle advancement: a dynamic structure for the treatment of severe congenital eyelid ptosis. Plast Reconstr Surg. 2004;113(6):1841-9; discussion 1850-1.

20. Lee V, Konrad H, Bunce C, Nelson C, Collin JR. Aetiology and surgical treatment of childhood blepharoptosis. Br J Ophthalmol. 2002;86(11):1282-6.

21. Lee MJ, Oh JY, Choung HK, Kim NJ, Sung MS, Khwarg SI. Frontalis sling operation using silicone rod compared with preserved fascia lata for congenital ptosis a three-year follow-up study. Ophthalmology. 2009;116(1):123-9.

22. Ben Simon GJ, Macedo AA, Schwarcz RM, Wang DY, McCann JD, Goldberg RA. Frontalis suspension for upper eyelid ptosis: evaluation of different surgical designs and suture material. Am J Ophthalmol. 2005;140(5):877-85.

23. Bagheri A, Aletaha M, Saloor H, Yazdani S. A randomized clinical trial of two methods of fascia lata suspension in congenital ptosis. Ophthal Plast Reconstr Surg. 2007;23(3):217-21.

24. Wagner RS, Mauriello JA Jr, Nelson LB, Calhoun JH, Flanagan JC, Harley RD. Treatment of congenital ptosis with frontalis suspension: a comparison of suspensory materials. Ophthalmology. 1984;91(3):245-8.

25. Berry-Brincat A, Willshaw H. Paediatric blepharoptosis: a 10year review. Eye. 2009;23(7):1554-9.

26. Mehta P, Patel P, Olver JM. Functional results and complications of Mersilene mesh use for frontalis suspension ptosis surgery. Br J Ophthalmol. 2004;88(3):361-4.

27. Junceda-Moreno J, Suárez-Suárez E, Dos-Santos-Bernardo V. Treatment of palpebral ptosis with frontal suspension: a comparative study of different materials. Arch Soc Esp Oftalmol. 2005;80(8):457-61.

28. Kersten RC, Bernardini FP, Khouri L, Moin M, Roumeliotis AA, Kulwin DR. Unilateral frontalis sling for the surgical correction of unilateral poor-function ptosis. Ophthal Plast Reconstr Surg. 2005;21(6):412-6; discussion 416-7.

29. Reifler DM. The tarsectomy operation of A.P.L. Gillet de Grandmont (1837-1894) and its periodic rediscovery. Doc Ophthalmol. 1995;89(1-2):153-62.

30. Patel SM, Linberg JV, Sivak-Callcott JA, Gunel E. Modified tarsal resection operation for congenital ptosis with fair levator function. Ophthal Plast Reconstr Surg. 2008;24(1):1-6.

31. Bassin RE, Putterman AM. Full-thickness eyelid resection in the treatment of secondary ptosis. Ophthal Plast Reconstr Surg. 2009;25(2):85-9.

32. Fasanella RM, Servat J. Levator resection for minimal ptosis: another simplified operation. Arch Ophthalmol. 1961;65:493-6.

33. Tyers A, Meyer-Rüsenberg HW. [Blepharophimosis ptosis epicanthus inversus syndrome (BPES) (corrected)]. Klin Monbl Augenheilkd. 2012;229(1):28-30. Review. German. Erratum in: Klin Monbl Augenheilkd. 2012;229(1):E1. 
34. Li H, Li D, Jie Y, Qin Y. Multistage correction of blepharophimosis: our rationale for 18 cases. Aesthetic Plast Surg. 2009;33(4):576-81.

35. Cahill KV, Bradley EA, Meyer DR, Custer PL, Holck DE, Marcet MM, et al. Functional indications for upper eyelid ptosis and blepharoplasty surgery: a report by the American Academy of Ophthalmology. Ophthalmology. 2011;118(12):2510-7.
36. Khwarg SI, Tarbet KJ, Dortzbach RK, Lucarelli MJ. Management of moderate-to-severe Marcus-Gunn jaw-winking ptosis. Ophthalmology. 1999;106(6):1191-6.

Corresponding author:

Luiz Angelo Rossato

Rua Cruzeiro do Sul, 220, Londrina/PR, Brazil - CEP: 86050-260

Email: luiz_rossato@hotmail.com 